\title{
Finding behavioral and network indicators of brain vulnerability
}

\author{
Nava Levit-Binnun* and Yulia Golland \\ School of Psychology, Interdisciplinary Center (IDC), Herzliya, Israel
}

\section{Edited by:}

João R. M. Oliveira, Federal

University of Pernambuco, Brazil

Reviewed by:

João R. M. Oliveira, Federal

University of Pernambuco, Brazil

Ana G. Hounie, University of Sao

Paulo, Brazil

\section{${ }^{*}$ Correspondence:}

Nava Levit-Binnun, School of

Psychology, Interdisciplinary Center

(IDC), Herzliya, P.O. Box 167,

Herzliya 46150, Israel.

e-mail: navalb@idc.ac.il
Resilience research has usually focused on identifying protective factors associated with specific stress conditions (e.g., war, trauma) or psychopathologies (e.g., post-traumatic stress disorder [PTSD]). Implicit in this research is the concept that resilience is a global construct, invariant to the unfavorable circumstances or the psychopathologies that may develop (i.e., the mechanisms underlying the resilience of an individual in all cases are expected to be similar). Here we contribute to the understanding of resilience-and its counterpart, vulnerability-by employing an approach that makes use of this invariant quality. We outline two main characteristics that we would expect from indicators of a vulnerable state: that they should appear across disorders regardless of specific circumstances, and that they should appear much before the disorder is evident. Next, we identify two sets of factors that exhibit this pattern of association with psychopathological states. The first was a set of "low-level" sensory, motor and regulatory irregularities that have been reported across the clinical literature; we suggest that these can serve as behavioral indicators of a vulnerable state. The second was the set of aberrations in network metrics that have been reported in the field of systems neuroscience; we suggest that these can serve as network indicators of a vulnerable state. Finally, we explore how behavioral indicators may be related to network indicators and discuss the clinical and research-related implications of our work.

Keywords: resilience, vulnerability, systems neuroscience, soft neurological signs, vulnerability indicators, vulnerability markers, psychopathology, secondary symptoms

\section{INTRODUCTION}

Resilience refers to the ability to maintain a state of normal equilibrium in the face of extremely unfavorable circumstances (Bonanno, 2004). The fact that some individuals have a relatively good psychological outcome despite circumstances that are expected to lead to serious negative consequences has led researchers to search for factors underlying resilience. Identifying the factors that increase one's ability to maintain a state of equilibrium in the face of extremities has important preventive value as well as implications for understanding mechanisms of resilience.

Resilience research has usually undertaken an approach that has focused on identifying protective factors associated with specific stress conditions (e.g., war, trauma, abuse) or with specific psychopathologies (e.g., post-traumatic stress disorder [PTSD]; e.g., Heinrichs et al., 2005; Admon et al., 2009; Kempton et al., 2009). With this approach, researchers have outlined a broad range of social, psychological, behavioral, biological, and neurobiological factors that describe individuals that have experienced adversity but have managed to overcome it. On the psychosocial level, factors such as positive emotions, active coping style, cognitive flexibility, moral compass, and social support have been shown to promote greater resilience in individuals facing extreme adversity (Masten, 2001; Haglund et al., 2007; Cicchetti, 2010). On the biological and neurobiological level, researchers have associated various hormones, neurochemicals, brain areas, specific neuronal activity and even genes to resilience mechanisms (e.g.,
Davidson, 2000; Caspi et al., 2003; Charney, 2004; Heinrichs et al., 2005; Haglund et al., 2007; Admon et al., 2009; Vialou et al., 2010; DeYoung et al., 2011).

Although much of resilience research has searched for protective factors in specific contexts, implicit across this work is the concept that resilience is a global construct, invariant to the unfavorable circumstances or the psychopathologies that may develop. That is, while an unfavorable circumstance can be one of many (e.g., psychological or external life stressors, aberrations in anatomical brain structures during development or neurodegeneration, chemical stressors, or brain hemorrhages) and while a wide range of psychopathologies can be triggered by each of these unfavorable circumstances, the mechanisms underlying the resilience of an individual in each of these cases are expected to be similar. Here we would like to contribute to understanding resilience—and its counterpart, vulnerability—by employing an approach that goes back to its underlying conceptualization and makes use of this invariant quality. Since in our context vulnerability and resilience are two sides of the same coin (a vulnerable brain is one that is expected to be less resilient) and since vulnerability is easier to detect than resilience, we will focus on vulnerability in the remainder of this manuscript.

How can looking at this invariant quality help advance our understanding of vulnerability? For one, it can assist in the determination of indicators of the vulnerability state, an important task with both clinical and research implications. Like the 
vulnerability state itself, indicators of vulnerability should also manifest this invariant quality. Thus indicators of vulnerability should display two main characteristics: first, we can expect them to be invariant to the unfavorable circumstance or the psychopathology that can be developed. In other words, when we look at vulnerability as an invariant global quality, we expect similar indicators to appear across individuals regardless of their specific risk factors. Second, if vulnerability is a global quality that describes an individual before encountering a stressor and developing a psychopathology, then we expect indicators of a vulnerable state to be evident much before any full-blown psychopathology appears. It follows that indicators should already exist in at-risk populations or in individuals that will later develop a psychopathology, and therefore we expect the indicators to have a predictive nature.

Here we identify two sets of indicators that adhere to the two main characteristics stipulated above. The first set is related to observations from developmental and clinical psychopathology regarding subtle impairments and irregularities in motor, sensory, and regulatory processes that occur in association with many psychopathologies. We review the pattern of appearance of these irregularities and show that they both appear in correlation with psychopathological symptoms and are predicative of psychopathology; thus they can serve as valuable behavioral indicators of a vulnerable state. The second set of indicators is from the rising field of systems neuroscience. We review reports from systems neuroscientists regarding irregularities in network metrics and show that these irregularities are found across psychopathologies and are predictors of psychopathology; thus they may be interesting candidates for network indicators of vulnerable states. Finally, we explore how behavioral indicators may be related to network indicators, and discuss the implications of our work.

\section{SENSORY, MOTOR AND REGULATORY IRREGULARITIES AS INDICATORS OF VULNERABILITY}

In the clinical and developmental psychopathology literature, disorders are characterized mainly by their distinguishing symptoms and behaviors, often referred to as primary symptoms. For example, autism is defined by difficulties in communication and restricted behavior, attention deficit hyperactivity disorder (ADHD) by attention deficits, schizophrenia by reality distortion and Alzheimer's disease by memory loss. Gaining much less attention, although widely described, are "low-level" irregularities that often accompany the primary symptoms. These irregularities appear across disorders and are sometimes termed by clinicians "secondary" or "non-specific" signs. They refer to subtle impairments in motor, sensory, and regulatory processes. Motor signs include motor coordination difficulties and impaired complex motor sequencing (Sanders and Keshavan, 1998; Chan et al., 2009). Sensory signs include deficits in sensory integration, modulation, and regulation (Sanders and Keshavan, 1998; Chan et al., 2009). Regulatory signs refer to difficulties in selfregulation (e.g., state control, self-calming, mood regulation, emotional, and behavioral control), and to problems with the regulation of arousal and sleeping and eating cycles (DeGangi et al., 2000). The non-specific nature of these regulatory, sensory, and motor irregularities has largely precluded their use as indicators of specific psychopathologies. However, in our approach, this non-specificity is actually an advantage as it means that the irregularities may be associated with a general state of vulnerability.

\section{SENSORY, MOTOR AND REGULATORY IRREGULARITIES ARE ASSOCIATED WITH SYMPTOMS OF PSYCHOPATHOLOGY}

Numerous publications have reported the existence of sensory, motor and regulatory irregularities in association with psychopathologies. With regard to sensory/motor irregularities, which are often described together, much clinical data has described their prevalence in individuals on the autistic spectrum (Ornitz, 1974; Jones and Prior, 1985; Tani et al., 2006; Liss et al., 2006; Ben-Sasson et al., 2007; Leekam et al., 2007; Bhat et al., 2011; for review see Reynolds and Lane, 2008 and Fournier et al., 2010) and in individuals with schizophrenia (e.g., Manschreck et al., 1985; Arango et al., 2000; Brown et al., 2002; Bombin et al., 2005; Javitt, 2009; for review see Chan et al., 2010a). In addition, in developmental disorders, non-specific sensory/motor symptoms have been reported in young children with minimal neurological impairment (Steinberg and Rendle-Short, 1977) and in children with ADHD (Piek et al., 1999; Mangeot et al., 2001; Yochman et al., 2004; Parush et al., 2007; Davis et al., 2009; Udal et al., 2009; for review see Reynolds and Lane, 2008), learning disorders (Ayres, 1978; Levinson, 1988), and dyslexia (Levinson, 1988; Brookes et al., 2010). Abnormalities in sensory and motor systems have also been documented in affective and psychiatric disorders such as anxiety (Erez et al., 2004; Emck et al., 2009; Shefer et al., 2010), depression (Carton et al., 1995; Emck et al., 2009), PTSD (McFarlane et al., 1993; Kremen et al., 2012), social anxiety disorder (Hofmann and Bitran, 2007), borderline personality disorder (Brown et al., 2009; for review see Reynolds and Lane, 2008); bipolar affective disorders (Negash et al., 2004), schizotypal personality disorder (Neumann and Walker, 2003; Mittal et al., 2007), and obsessive compulsive disorder (OCD; Karadag et al., 2011; Dar et al., 2012). Sensory and motor abnormalities have also been observed in neurological and degenerative states such as Alzheimer's disease (e.g., Seidl et al., 2009) and traumatic brain injury (Annoni et al., 1992; Galvin et al., 2009) and even in normally aging individuals (Chan et al., 2011).

With regard to irregularities in regulatory processes, difficulties in self-regulation and in sleeping and eating cycles have been described across many psychopathologies. For example, abnormalities in sleeping and eating patterns are prevalent in children with autism spectrum disorder (Schreck et al., 2004; for review see Richdale and Schreck, 2009), in children with ADHD (Owens et al., 2002; Shochat et al., 2009) and in children with mental retardation and severe behavioral disorders (Piazza et al., 1996). Sleep/eating irregularities are associated with affective disorders (Modell et al., 2005), such as OCD (Insel et al., 1982; Alfano and Kim, 2011), major depression, (Breslau et al., 1996), and psychiatric disorders (Ivanenko and Johnson, 2008; Sakar et al., 2010). Regulatory difficulties are also well-documented in degenerative disorders such as Alzheimer's disease (Yesavage et al., 2004).

One might argue that the above irregularities are a direct result of the individual's psychopathology. However, as we will demonstrate below, these irregularities are also present in healthy 
individuals who display more negative mental health symptoms than healthy individuals without these irregularities. This fact lends evidence to the argument that these sensory, motor and regulatory irregularities are not the consequence of psychopathology but rather a characteristic of an underlying vulnerability to psychopathology.

Many studies have shown that individuals with irregularities in emotion regulation and reactivity exhibit more psychopathology related signs (e.g., see Davidson, 2000). With regard to sensory/motor irregularities, healthy individuals with extreme sensory reactivity are more likely to display signs of anxiety and depression (Kinnealey and Fuiek, 1999; Balaban, 2002; Liss et al., 2005, 2008; Goldsmith et al., 2006; Engel-Yeger and Dunn, 2011; Levit-Binnun et al., submitted) and stress (Levit-Binnun et al., submitted). These individuals also display higher signs of alexithymia (inability to identify, describe, and interpret emotional states; Liss et al., 2008), autistic characteristics (Liss et al., 2008), social phobia (Neal et al., 2002) and avoidant and borderline personality traits (Meyer and Caver, 2000; Meyer et al., 2005). Preschoolers and school-aged children with sensory regulation dysfunction (e.g., sensory over-responsivity) were more likely to display early and co-occuring internalizing and externalizing behaviors, lower levels of concurrent adaptive social behaviors and more psychiatric symptoms (Ben-Sasson et al., 2009; Gouze et al., 2009). Similarly, preschoolers with motor coordination difficulties exhibited negative emotional symptoms such as signs of depression and anxiety (Piek et al., 2008)

In sum, secondary motor and regulatory irregularities appear in association with psychopathology, both in individuals displaying full-blown symptoms and in those displaying mild, nonclinical signs of psychopathology. These irregularities thus adhere to the first characteristic of an indicator of vulnerability that we set forth above: they are invariant to the unfavorable circumstance or the psychopathology that can be developed.

\section{SENSORY, MOTOR AND REGULATORY IRREGULARITIES APPEAR BEFORE PSYCHOPATHOLOGY IS EVIDENT}

The second characteristic of an indicator of vulnerability that we set forth above was that they should be evident much before any full-blown psychopathology appears. That is, indicators of vulnerability should already exist in at-risk populations or in individuals long before they develop a psychopathology. Although this characteristic is reminiscent of the concept of endophenotypeswhich are heritable biomarkers expressed long before the disease is manifested, and are also present in family members at-risk for the disease (Gottesman and Gould, 2003) - it is important to note that we use the word "indicators" here to describe a broader set of signs that, unlike endophenotypes, include those with a non-genetic component.

A number of clinical studies have examined the occurrence of specific sensory irregularities in infants at-risk for psychopathology and found these irregularities to be present much before the full-blown symptoms appear. For example, sensory difficulties precede autism symptoms in most infants that will later develop autism spectrum disorder (Baranek, 1999; Bryson et al., 2007; Rogers, 2009). DeGangi and Greenspan (1988) found that atrisk infants (i.e., those assessed as having a difficult temperament or a developmental delay relative to their age group) were more likely to demonstrate tactile over-sensitivity than infants without any reported difficulty. In addition, poor ocular-motor control and vestibular deficits were significant as compared to normal infants. Other studies have found vestibular dysfunction in infants exhibiting later motor and speech delays (Quirós, 1976) and in infants at-risk for schizophrenia (Fish and Dixon, 1978).

Other studies have focused on motor irregularities as predictors of psychopathologies. Motor coordination difficulties assessed in at-risk children predicted later adult schizophrenia symptoms and outcome (Schiffman et al., 2009). Significantly more motor difficulties were observed in children that would later develop autism (Baranek, 1999; Bryson et al., 2007; Ozonoff et al., 2008). In a prospective study following 401 toddlers, motor abilities were found to be predictive of ADHD (Kroes et al., 2002). In toddlers at-risk for familial dyslexia, researchers found a relationship between motor development at infanthood and the level of language skills at toddlerhood (Viholainen et al., 2006).

Additional research has centered on a subset of abnormalities in both sensory and motor processes (often called "neurological soft signs") and has found them to be predictive of negative outcome. In several prospective epidemiological studies, an association was found between neurological soft signs and the development of anxiety, depression and obsessive symptoms overtime (Shaffer et al., 1985; Pine et al., 1993). Fellick et al. (2001) studied the occurrence of neurological soft signs in mainstream pupils and found that children with higher scores on the soft sign battery had worse performance on measures of cognition, coordination and behavior. The same children were also more likely to have cognitive impairment, coordination problems, or ADHD. Significantly more soft neurological signs were found in children and relatives with a higher genetic risk for schizophrenia (Walker et al., 1999; Mittal et al., 2007; for review see Chan et al., 2010b; Neelam et al., 2011) and in those that later became adult schizophrenics (Asarnow et al., 1995; Schiffman et al., 2009). Whether a particular vulnerable child became psychotic, or developed a less severe personality disorder, was related to the severity of his early soft signs interacting with his unique environment (Fish and Dixon, 1978). Interestingly, recent studies on twins have found that soft neurological signs represent vulnerability to PTSD: not only did combat veterans with PTSD have significantly more soft neurological signs than combat veterans without PTSD, but their unexposed co-twins had significantly more soft neurological signs than the unexposed co-twins of the veterans without PTSD (Gurvits et al., 2006; Kremen et al., 2012).

With regard to regulatory deficiencies, evidence in the developmental literature indicates that self-regulatory difficultiesspecifically those related to the regulation of affect and moodare early risk factors for developing a later developmental or psychiatric/affective psychopathology (e.g., Davidson, 2000; DeGangi et al., 2000; Gomez and Baird, 2005; Koenen, 2006; Bryson et al., 2007; Lewis et al., 2008; Amstadter, 2008; Cicchetti, 2010). However, little attention has been given to the broader range of regulatory processes, such as the regulation of sleeping and eating cycles. In several prospective studies, DeGangi and colleagues showed that fussy babies exhibiting sleeping or eating problems and high-sensitivity to sensory stimulation had a much 
greater chance of developing a disorder at 36 months as compared to non-fussy babies. In addition, the group of babies who had more regulatory difficulties had a $95 \%$ probability of developing some kind of clinical diagnosis related to motor, language, and cognitive difficulties and/or parent-child relational problems at 36 months (DeGangi et al., 1993, 2000). In another study examining fussy babies, DeSantis et al. (2004) found that hours of fussing during infancy significantly correlated with greater inattention, higher emotional reactivity and sensory sensitivity, poorer environmental coping, and more externalizing behavior at 3-8 years of age. In older children, sleeping/eating irregularities have been associated with the subsequent development of various affective disorders (Gregory and O'Connor, 2002; Ong et al., 2006). Sleep irregularities, such as abnormalities in REM sleep, have also been found in healthy adults who have relatives with affective disorders (Modell et al., 2005). In addition, sleep irregularities have been proposed as a marker for psychiatric disorders (Lauer et al., 1995) and sleep insomnia has recently been suggested as a risk factor for Alzheimer's disease that may even play a direct role in the progression of the disorder (Wang et al., 2011).

To summarize, the brief review above demonstrated the association of non-specific sensory, motor and regulatory irregularities with psychopathology (both in the full-blown disease but also in healthy individuals with mild subclinical signs) and in individuals at-risk for developing a psychopathology. This pattern of occurrence matches the two main characteristics we outlined above, and suggests that the irregularities can be behavioral indicators of a general state of vulnerability. Although regulation of emotion and mood has already been associated with resilience (Cicchetti, 2010), sensory, and motor irregularities, as well as dysregulation in sleeping and eating cycles, have rarely been discussed in the direct context of vulnerability and resilience. Thus the approach we undertook here-examining the invariant qualities of vulnerability across disorders-allowed us to outline novel candidate indicators that at first glance may not appear relevant in the context of vulnerability and resilience.

\section{PATTERNS OF NETWORK ABERRATIONS AS INDICATORS OF VULNERABILITY}

Network analysis uses graph theoretical tools to assess various network metrics from connectivity data. These network metrics are a measure of how well the brain functions, and indicate the efficiency of information transfer across the whole network and the ability of large-scale networks within the brain to switch between engaged and disengaged modes of function. They are also a measure of the brain's resilience, or in systems neuroscience terms, "brain robustness," which is defined as the robustness of the system to intrinsic and extrinsic perturbations (Kitano, 2004; Sporns, 2010). This robustness is supported by global network mechanisms (Sporns, 2010) that arise in specific network configurations and can limit the effects of potentially disruptive perturbations (Achard et al., 2006; Bassett and Bullmore, 2006).

An example of a network metric is how much the brain adheres to a global network architecture called a "small world network" that describes a configuration in which most nodes are not neighbors, but can be reached from every other node by a small number of steps (Menon, 2011). Other network metrics include measures of local connectivity levels (such as the clustering and modularity of various nodes in the network), measures of global integration (such as the average path length between two nodes, which is indicative of how efficiently the network is connected) and measures of the importance of specific hub nodes (such as the centrality of specific nodes; Sporns, 2010). Aberration in these network metrics can result in general network failure, which affects network robustness as well as efficient information transfer, and can cause deficits in the access, engagement, and disengagement of large-scale networks (Dosenbach et al., 2008; Sporns, 2010).

Recent methodological advances concerned with the study and analysis of complex networks in the brain are allowing neuroscientists to extract these network metrics from a large body of functional and structural connectivity data obtained from diffusion tensor imaging (DTI), functional magnetic resonance imaging (fMRI), magnetoencephalography (MEG) and electroencephalography (EEG) studies. Analysis of connectivity data from many studies examining various states of psychopathologies has found common aberrations in various network metrics (Sporns, 2010; Menon, 2011). For example, when comparing structural data from schizophrenia patients and healthy controls, schizophrenia brains show a loss of "small world" architecture as measured by a significantly lower clustering coefficient, longer characteristic path lengths and dysfunctional central hubs (Bassett et al., 2008; van den Heuvel et al., 2010). Abnormalities in these network metrics were also reported when functional connectivity data from patients with Alzheimer's disease was compared to controls (Stam et al., 2007, 2009; Supekar et al., 2008; SanzArigita et al., 2010). Network abnormalities were also observed in many other disorders, including autism (Belmonte et al., 2004; Just et al., 2007), ADHD (Castellanos et al., 2008; Wang et al., 2009), and dementia (Pievani et al., 2011). Taken together, these studies suggest that network aberrations are a general characteristic of psychopathologies and thus they adhere to the first characteristic that we outlined for indicators of vulnerability.

In addition, initial evidence suggests that these network aberrations also adhere to the second characteristic we expect of vulnerability indicators, namely, that they should have a predictive nature. Results of a very recent study (Yao et al., 2010) indicated that abnormalities in network metrics can be detected before a psychopathology is evident. In the study, researchers measured network parameters from patients with Alzheimer's disorder (AD), individuals with mild cognitive impairment disorder (MCI) and healthy age-matched controls. They found the greatest clustering coefficient and the longest absolute path length in patients with $\mathrm{AD}$, which indicates that the small world organization of the cortical network was the least optimal in AD. The small world measures of the MCI network exhibited intermediate values between $\mathrm{AD}$ and the normal aging controls. Given that MCI is considered to be the transitional stage between normal aging and $\mathrm{AD}$, these findings suggest that network aberrations are evident before the full-blown $\mathrm{AD}$ symptoms appear. In another study, Dazzan et al. (2011) obtained MRI data from 102 individuals considered to be at a very high-risk for schizophrenia and subsequently followed them for one year. Those that developed schizophrenia or other forms of psychosis had more volumetric 
abnormalities in distributed brain areas at the time of the MRI scan. Although the authors did not perform a graph-theoretical analysis, this study provides further evidence that network aberrations predate the onset of a psychopathology.

Thus, a pattern similar to the one described above for behavioral irregularities seems to arise in the systems neuroscience framework with regard to network aberrations. Evidence for network aberrations that give rise to network failure have been observed across psychopathologies, and there is initial evidence that these irregularities appear before the psychopathology is evident. Hence, network aberrations fit both of the characteristics that we proposed as indicators of vulnerability. Although systems neuroscience is still in its infancy, and the evidence here is less conclusive than that from the well-established fields of developmental and clinical psychopathology, the emerging pattern leads us to suggest that network aberrations can serve as network indicators of brain vulnerability.

\section{DISCUSSION}

In this review we used the invariant quality of vulnerability to outline two main characteristics that we would expect from indicators of a vulnerable state: that they should appear across disorders regardless of specific circumstances, and that they should appear much before the disorder is evident. We were able to identify two sets of factors that exhibited this pattern of association with psychopathological states. The first was "low-level" sensory, motor and regulatory irregularities that have been reported across the clinical literature. The second was the set of aberrations in network metrics that have been reported in the field of systems neuroscience. Both of these sets were therefore proposed as indicators of vulnerability, albeit at different levels of description.

By searching for indicators based on patterns of invariance, rather than based on specific pathologies or risk factors, we were able to identify novel factors that at first glance may not seem relevant to resilience. Unlike, for example, the cortisol hormone that is known to be related to stress and is therefore expected to relate to vulnerability, the relationship between vulnerability and sensory/motor difficulties, or between vulnerability and irregularities in eating or sleeping cycles, is less direct. However, the fact that these relationships to vulnerability are not immediately visible should not deter us from investigating them more seriously. Indeed, leading researchers in the resilience field have recently suggested that resilience and vulnerability are dynamic developmental constructs that can arise from, and be influenced by, a complex dynamic interaction between multiple brain processes (Masten, 2006; Cicchetti, 2010). This implies that various brain processes that are not directly associated with stress mechanisms, such as the ones we suggested here, may still affect vulnerability through non-linear interactions with other processes. For example, an individual who has sensory hypersensitivity may find dyadic interactions stressful. This can lead to self-deprivation of the social environment, which is considered important for enhancing resilience.

Although the two sets of indicators proposed here come from different levels of description — one at the behavioral level and the other at the network level-the fact that they display similar patterns suggests that they may be related. Indeed, a recent set of experiments has shown that "soft neurological signs" (see above) are associated with structural brain irregularities in individuals exhibiting these signs (Dazzan et al., 2004, 2006; Janssen et al., 2009; Thomann et al., 2009; Heuser et al., 2011). This relation can also be supported theoretically using the network description of vulnerability as a state in which network robustness is compromised following network failure. Network failure not only leads to less robustness but also to less efficient information transfer and computation throughout the network, as well as to the disruption of mechanisms in charge of maintaining dynamic balance (Sporns, 2010). As a result, network failure should affect general network function, including the most basic input, output, and regulation processes. Thus, irregularities in sensory, motor, and regulation processes can be viewed as co-arising with the loss of robustness due to network failure.

\section{IMPLICATIONS AND FUTURE DIRECTIONS}

Finding indicators of brain vulnerability has both clinical and research applications. On the clinical level it can enable the identification of vulnerable individuals at pre-traumatic stages and help inform the design of preventive resilience-boosting interventions. The behavioral indicators we outlined here-such as motor coordination difficulties, sensory hypersensitivity and fussinesscan be recognized even by a non-professional eye and may be addressed with simple parent-based interventions (e.g., Klein et al., 2008; Jaegermann and Klein, 2010). Such interventions could enhance current preventive programs that aim to avoid the snowballing of problems and promote positive development (Masten, 2006). In the future, as systems neuroscience becomes more established, it is likely that network indicators will be used as part of general screening tests to detect vulnerable individuals (Wen et al., 2011).

On the research level, the ability to identify vulnerable individuals at pre-traumatic periods would enable us to further explore the differences between resilient and vulnerable brains, as well as examine the temporal dynamics of vulnerable brains, before and after they are impacted by a stressor (Admon et al., 2009). Moreover, to date, most resilience and vulnerability research has focused on specific at-risk populations (e.g., firefighters or soldiers; Heinrichs et al., 2005) or has involved conducting large-cohort prospective studies (Cicchetti, 2010). Therefore, the ability to identify vulnerable individuals would facilitate research that focuses only on a subset of individuals with brain vulnerability.

Finally, viewing vulnerability as an invariant state can assist in the development of neurobiological tools to measure brain vulnerability. Such tools would enable the direct testing of the association of possible indicators, such as those proposed here, with brain vulnerability. As mentioned above, in the systems neuroscience framework brain resilience is defined in general terms of "robustness to perturbation." This view implies that measuring the reaction of large brain networks to targeted perturbations can serve as a means of directly studying brain resilience and vulnerability. Various tools can serve the purpose of measuring robustness to perturbations, one example being transcranial magnetic stimulation (TMS), which is widely used to induce or inhibit activity in a localized brain area. Recently, we used single 
TMS perturbations to study the stability of a specific network in a healthy state and in a disordered schizophrenia state (LevitBinnun et al., 2007). We found signs of network vulnerabilities in the schizophrenia state that appeared only in response to the TMS perturbations and that were not observed in the healthy state. Future work should continue this direction in order to develop neurobiological tools that can quantitatively measure brain vulnerability and resilience. Indicators that enable the identification of a vulnerable brain state, together with tools that directly measure brain vulnerability, can greatly advance the

\section{REFERENCES}

Achard, S., Salvador, R., Whitcher, B., Suckling, J., and Bullmore, E. (2006). A resilient, low-frequency, small-world human brain functional network with highly connected association cortical hubs. $J$. Neurosci. 26, 63-72.

Admon, R., Lubin, G., Stern, O., Rosenberg, K., Sela, L., Ben-Ami, H., and Hendler, T. (2009). Human vulnerability to stress depends on amygdala's predisposition and hippocampal plasticity. Proc. Natl. Acad. Sci. U.S.A. 16, 14120-14125.

Alfano, C. A., and Kim, K. L. (2011). Objective sleep patterns and severity of symptoms in pediatric obsessive compulsive disorder: a pilot investigation. J. Anxiety Disord. 25, 835-839.

Amstadter, A. B. (2008). Emotion regulation and anxiety disorders. $J$. Anxiety Disord. 22, 211-221.

Annoni, J. M., Beer, S., and Kesselring, J. (1992). Severe traumatic brain injury-epidemiology and outcome after 3 years. Disabil. Rehabil. 14, 23-26.

Arango, C., Kirkpatrick, B., and Buchanan, R. W. (2000). Neurological signs and the heterogeneity of schizophrenia. Am. J. Psychiatry 157, 560-565.

Asarnow, R. F., Brown, W., and Strandburg, R. (1995). Children with a schizophrenic disorder: neurobehavioral studies. Eur. Arch. Psychiatry Clin. Neurosci. 245, 70-79.

Ayres, A. J. (1978). Learning disabilities and the vestibular system. J. Learn. Disabil. 11, 30-41.

Balaban, C. D. (2002). Neural substrates linking balance control and anxiety. Physiol. Behav. 77, 469-475.

Baranek, G. T. (1999). Autism during infancy: a retrospective video analysis of sensory-motor and social behaviors at 9-12 months of age. J. Autism Dev. Disord. 29, 213-224.

Bassett, D. S., and Bullmore, E. (2006). Small-world brain networks. Neuroscientist 12, 512-523.
Bassett, D. S., Bullmore, E., Verchinski, B. A., Mattay, V. S., Weinberger, D. R., and Meyer-Lindenberg, A. (2008). Hierarchical organization of human cortical networks in health and schizophrenia. J. Neurosci. 28, 9239-9248.

Belmonte, M. K., Allen, K., BeckelMitchener, A., Boulanger, L. M., Carper, R. A., and Webb, S. J. (2004). of brain connectivity. J. Neurosci. 24 , 9228-9231.

Ben-Sasson, A., Carter, A. S., and Briggs-Gowan, M. J. (2009). Sensory over-responsivity in elementary school: prevalence and social-emotional correlates. J. Abnorm. Child Psychol. 37, 705-716.

Ben-Sasson, A., Cermak, S. A., Orsmond, G. I., Carter, A. S., Kadles, M. B., and Dunn, W. lation behaviors in toddlers with autism. Am. J. Occup. Ther. 61, 584-592.

Bhat, A. N., Landa, R. J., and Galloway, J. C. (2011). Current perspectives on motor functioning in infants, children, and adults with autism spectrum disorders. Phys. Ther. 91, 1116-1129.

Bombin, I., Arango, C., and Buchanan, R. W. (2005). Significance and meaning of neurological signs in schizophrenia: two decades later. Schizophr. Bull. 31, 962-977.

Bonanno, G. A. (2004). Loss, trauma, and human resilience: have we underestimated the human capacity to thrive after extremely aversive events? Am. Psychol. 59, 20-28.

Breslau, N., Roth, T., Rosenthal, L., and Andreski, P. (1996). Sleep disturbance and psychiatric disorders: a longitudinal epidemiological study of young adults. Biol. Psychiatry 39, 411-418.

Brookes, R. L., Tinkler, S., Nicolson, R. I., and Fawcett, A. J. (2010). Striking the right balance: motor difficulties in children and adults with dyslexia. Dyslexia 16, 358-373.

Brown, C., Cromwell, R. L., Filion, D., Dunn, W., and Tollefson, N. (2002). Autism and abnormal development (2007). Extreme sensory modu-

understanding of how vulnerability and resilience mechanisms emerge from the brain's complexity and its interaction with the environment.

\section{ACKNOWLEDGMENTS}

We gratefully acknowledge Prof. Elisha Moses for his support and encouragement and Prof. Matti Mintz and Dr. Yossi Arzouan for their insightful comments. We also wish to acknowledge the many therapists and clinicians working with individuals with difficulties from whose wisdom and knowledge we have been inspired.

Sensory processing in schizophrenia: missing and avoiding information. Schizophr. Res. 55, 187-195.

Brown, S., Shankar, R., and Smith, K. (2009). Borderline personality disorder and sensory processing impairment. Prog. Neurol. Psychiatry 13, 10-16.

Bryson, S. E., Zwaigenbaum, L. Brian, J., Roberts, W., Szatmari, P. Rombough, V., and McDermott, C. (2007). A prospective case series of high-risk infants who developed autism. J. Autism Dev. Disord. 37, 12-24.

Carton, S., Morand, P., Bungenera, C. and Jouvent, R. (1995). Sensation seeking and emotional disturbances in depression: relationship and evolution. J. Affect. Disord. 34 219-225.

Caspi, A., Sugden, K., Moffitt, T. E. Taylor, A., Craig, I. W., Harrington, H., McClay, J., Mill, J., Martin, J., Braithwaite, A., and Poulton, R. (2003). Influence of life stress on depression: moderation by a polymorphism in the 5-HTT gene. Science 301, 386-389.

Castellanos, F. X., Margulies, D. S. Kelly, A. M. C., Uddin, L. Q., Ghaffari, M., Kirsch, A., Shaw, D., Shehzad, Z., Martino, A. D., Biswal, B., Sonuga-Barke, E. J., Rotrosen, J., Adler, L. A., and Milham, M. P. (2008). Cingulateprecuneus interactions: a new locus of dysfunction in adult attentiondeficit/hyperactivity disorder. Biol. Psychiatry 63, 332-337.

Chan, R. C. K., Wang, Y., Wang, L., Chen, E. Y. H., Manschreck, T. C., Li, Z. J., Yu, X., and Gong, Q. Y. (2009). Neurological soft signs and their relationships to neurocognitive functions: a revisit with the structural equation modeling design. PLoS One 4, e8469. doi: 10.1371/journal.pone. 0008469

Chan, R. C. K., Xu, T., Heinrichs, R. W., Yu, Y., and Wang, Y. (2010a). Neurological soft signs in schizophrenia: a meta-analysis. Schizophr. Bull. 36, 1089-1104.
Chan, R. C., Xu, T., Heinrichs, R. W. Yu, Y., and Gong, Q. Y. (2010b). Neurological soft signs in nonpsychotic first-degree relatives of patients with schizophrenia: a systematic review and metaanalysis. Neurosci. Biobehav. Rev. 34, 889-896.

Chan, R. C., Xu, T., Li, H. J., Zhao, Q., Liu, H. H., Wang, Y., Yan, C., Cao, X. Y., Wang, Y. N., and Shi, Y. F. (2011). Neurological abnormalities and neurocognitive functions in healthy elder people: a structural equation modeling analysis. Behav. Brain Funct. 10, 7-32.

Charney, D. S. (2004). Psychobiological mechanisms of resilience and vulnerability: implications for successful adaptation to extreme stress. Am. J. Psychiatry 161, 195-216.

Cicchetti, D. (2010). Resilience under conditions of extreme stress: a multilevel perspective. World Psychiatry 9, 145-154.

Dar, R., Kahn, D. T., and Carmeli, R. (2012). The relationship between sensory processing, childhood rituals and obsessive compulsive symptoms. J. Behav. Ther. Exp. Psychiatry 43, 679-684.

Davidson, R. J. (2000). Affective style, psychopathology, and resilience: brain mechanisms and plasticity. Am. Psychol. 55, 1196-1214.

Davis, A. S., Pass, L. A., Finch, W. H., Dean, R. S., and Woodcock, R. W. (2009). The canonical relationship between sensory-motor functioning and cognitive processing in children with attention-deficit/hyperactivity disorder. Arch. Clin. Neuropsychol. 24, 273-286.

Dazzan, P., Morgan, K. D., Chitnis, X., Suckling, J., Morgan, C., Fearon, P., McGuire, P. K., Jones, P. B., Leff, J., and Murray, R. M. (2006). The structural brain correlates of neurological soft signs in healthy individuals. Cereb. Cortex 16, 1225-1231.

Dazzan, P., Morgan, K. D., Orr, K. G., Hutchinson, G., Chitnis, X., Suckling, J., Fearon, P., Salvo, J., McGuire, P. K., Mallett, R. M., Jones, P. B., Leff, J., and Murray, R. 
M. (2004). The structural brain correlates of neurological soft signs in ÆSOP first-episode psychoses study. Brain 127, 143-153.

Dazzan, P., Soulsby, B., Mechelli, A., Wood, S. J., Velakoulis, D., Phillips, L. J., Yung, A. R., Chitnis, X., Lin, A., Murray, R. M., McGorry, P. D., McGuire, P. K., and Pantelis, C. (2011). Volumetric abnormalities predating the onset of schizophrenia and affective psychoses: an MRI study in subjects at ultrahigh risk of psychosis. Schizophr. Bull. (Epub ahead of print).

DeGangi, G. A., Breinbauer, C., Doussard-Roosevelt, J., Porges, S., and Greenspan, S. I. (2000). Prediction of childhood problems at three years in children experiencing disorders of regulation during infancy. Infant Ment. Health J. 21, 156-175.

DeGangi, G. A., Porges, S. W., Sickel, R. Z., and Greenspan, S. T. (1993). Four year follow up of a sample of regulatory disordered infants. Infant Ment. Health J. 14, 330-343.

DeGangi, G. A., and Greenspan, S. I. (1988). The development of sensory functions in infants. Phys. Occup. Ther. Pediatr. 8, 21-33.

DeSantis, A. M., Coster, W. J., Bigsby, R., and Lester, B. M. (2004). Colic and fussing in infancy and sensory processing at 3-8 years of age. Infant Ment. Health J. 25, 522-539.

DeYoung, C. G., Cicchetti, D., and Rogosch, F. A. (2011). Moderation of the association between childhood maltreatment and neuroticism by the corticotropin-releasing hormone receptor 1 gene. J. Child Psychol. Psychiatry 52, 898-906.

Dosenbach, N. U. F., Fair, D. A., Cohen, A. L., Schlaggar, B. L., and Petersen, S. E. (2008). A dual-networks architecture of top-down control. Trends Cogn. Sci. 12, 99-105.

Emck, C., Bosscher, R., Beek, P., and Doreleijers, T. (2009). Gross motor performance and self-perceived motor competence in children with emotional, behavioral, and pervasive developmental disorders: a review. Dev. Med. Child Neurol. 51, 501-517.

Engel-Yeger, B., and Dunn, W. (2011). The relationship between sensory processing difficulties and anxiety level of healthy adults. Br. J. Occup. Ther. 74, 210-216.

Erez, O., Gordon, C. R., Sever, J., Sadeh, A., and Mintz, M. (2004). Balance dysfunction in childhood anxiety: findings and theoretical approach. J. Anxiety Disord. 18, 341-356.

Fellick, J. M., Thomson, A. P., Sills, J., and Hart, C. A. (2001). Neurological soft signs in mainstream pupils. Arch. Dis. Child. 85, 371-374.

Fish, B., and Dixon, W. J. (1978). Vestibular hyporeactivity in infants at risk for schizophrenia: association with critical developmental disorders. Arch. Gen. Psychiatry 5, 963-971.

Fournier, K. A., Hass, C. J., Naik, S. K., Lodha, N., and Cauraugh, J. H. (2010). Motor coordination in autism spectrum disorders: a synthesis and meta-analysis. J. Autism Dev. Disord. 40, 1227-1240.

Galvin, J., Froude, E. H., and Imms, C. (2009). Sensory processing abilities of children who have sustained traumatic brain injuries. Am. J. Occup. Ther. 63, 701-709.

Goldsmith, H. H., Van Hulle, C. A., Arneson, C. L., Schreiber, J. E., and Gernsbacher, M. A. (2006). A population-based twin study of parentally reported tactile and auditory defensiveness in young children. J. Abnorm. Child Psychol. 34, 393-407.

Gomez, C. R., and Baird, S. (2005). Identifying early indicators for autism in self-regulation difficulties. Focus Autism Other Dev. Disabl. 20, 106-116.

Gottesman, I. I., and Gould, T. D. (2003). The endophenotype concept in psychiatry: etymology and strategic intentions. Am. J. Psychiatry 160, 636-645.

Gouze, K. R., Hopkins, J., LeBailly, A., and Lavigne, J. V. (2009). Reexamining the epidemiology of sensory regulation dysfunction and comorbid psychopathology. J. Abnorm. Child Psychol. 37, 1077-1087.

Gregory, A. M., and O'Connor, T. G. (2002). Sleep problems in childhood: a longitudinal study of developmental change and association with behavioral problems. J. Am. Acad. Child Adolesc. Psychiatry 41, 964-971.

Gurvits, T. V., Metzger, L. J., Lasko, N. B., Cannistraro, P. A., Tarhan, A. S., Gilbertson, M. K., Orr, S. P., Charbonneau, A. M., Wedig, M. M., and Pitman, K. R. (2006). Subtle neurologic compromise as a vulnerability factor for combatrelated posttraumatic stress disorder. Arch. Gen. Psychiatry 63, 571-576.

Haglund, M. E. M., Nestadt, P. S., Cooper, N. S., Southwick, S. M., and Charney, D. S. (2007). Psychobiological mechanisms of resilience: relevance to prevention and treatment of stress-related psychopathology. Dev. Psychopathol 19, 889-920.
Heinrichs, M., Wagner, D., Schoch, W., Soravia, L. M., Hellhammer, D. H. and Ehlert, U. (2005). Predicting posttraumatic stress symptoms from pretraumatic risk factors: a 2-year prospective follow-up study in firefighters. Am. J. Psychiatry 162, 2276-2286.

Heuser, M., Thomann, P. A., Essig, M., Bachmann, S., and Schröder, J. (2011). Neurological signs and morphological cerebral changes in schizophrenia: an analysis of NSS subscales in patients with first episode psychosis. Psychiatry Res. 192, 69-76.

Hofmann, S. G., and Bitran, S. (2007). Sensory-processing sensitivity in social anxiety disorder: relationship to harm avoidance and diagnostic subtype. J. Anxiety Disord. 21, 944-954.

Insel, T. R., Gillin, J. C., Moore, A., Mendelson, W. B., Loewenstein, R J., and Murphy, D. L. (1982). The sleep of patients with obsessivecompulsive disorder. Arch. Gen. Psychiatry 39, 1372-1377.

Ivanenko, A., and Johnson, K. (2008). Sleep disturbances in children with psychiatric disorders. Semin Pediatr. Neurol. 15, 70-78.

Jaegermann, N., and Klein, P. S. (2010). Enhancing mothers' interactions with toddlers who have sensoryprocessing disorders. Infant Ment. Health J. 31, 291-311.

Janssen, J., Diaz-Caneja, A., Reig, S. Bombìn, I., Mayoral, M., Parellada, M., Graell, M., Moreno, D., Zabala, A., Vazquez, V. G., Desco, M., and Arango, C. (2009). Brain morphology and neurological soft signs in adolescents with first-episode psychosis. Br. J. Psychiatry 195, 227-233.

Javitt, D. C. (2009). Sensory processing in schizophrenia: neither simple nor intact. Schizophr. Bull. 35, 1059-1064.

Jones, V., and Prior, M. (1985). Motor imitation abilities and neurological signs in autistic children. J. Autism Dev. Disord. 15, 37-46.

Just, M. A., Cherkassky, V. L., Keller, T. A., Kana, R. K., and Minshew, N. J. (2007). Functional and anatomical cortical underconnectivity in autism: evidence from an fMRI study of an executive function task and corpus callosum morphometry. Cereb. Cortex 17, 951-961.

Karadag, F., Tumkaya, S., Kırtas, D., Efe, M., Alacam, H., and Oguzhanoglu, N. K. (2011). Neurological soft signs in obsessive compulsive disorder with good and poor insight. Prog. Neuropsychopharmacol. Biol. Psychiatry 35, 1074-1079.
Kempton, M. J., Haldane, M., Jogia, J., Grasby, P. M., Collier, D., and Frangou, S. (2009). Dissociable brain structural changes associated with predisposition, resilience, and disease expression in bipolar disorder. J. Neurosci. 29, 10863-10868.

Kinnealey, M., and Fuiek, M. (1999). The relationship between sensory defensiveness, anxiety, depression and perception of pain in adults. Occup. Ther. Int. 6, 195-206.

Kitano, H. (2004). Biological robustness. Nat. Rev. Genet. 5, 826-837.

Klein, P. S., Laish-Mishali, R., and Jaegermann, N. (2008). Differential treatment of toddlers with sensory processing disorders in relation to their temperament and sensory profile. J. Dev. Process. 3, 52-29.

Koenen, K. C. (2006). Developmental epidemiology of PTSD selfregulation as a central mechanism. Ann. N.Y. Acad. Sci. 1071, 255-266.

Kremen, W. S., Koenen, K. C., Afari, N. and Lyons, M. J. (2012). Twin studies of posttraumatic stress disorder: differentiating vulnerability factors from sequelae. Neuropharmacology 62, 647-653.

Kroes, M., Kessels, A. G. H., Kalff, A. C., Feron, F. J. M., Vissers, Y. L. J., Jolles, J., and Vles, J. S. H. (2002). Quality of movement as predictor of ADHD: results from a prospective population study in 5- and 6year old children. Dev. Med. Child Neurol. 44, 753-760.

Lauer, C. J., Schreiber, W., Holsboer, F., and Krieg, J. C. (1995). In quest of identifying vulnerability markers for psychiatric disorders by allnight polysomnography. Arch. Gen. Psychiatry 52, 145-153.

Leekam, S. R., Nieto, N., Libby, S. J., Wing, L., and Gould, J. (2007). Describing the sensory abnormalities of children and adults with autism. J. Autism Dev. Disord. 37, 894-910.

Levinson, H. N. (1988). The cerebellarvestibular basis of learning disabilities in children, adolescents and adults: hypothesis and study. Percept. Mot. Skills 67, 983-1006.

Levit-Binnun, N., Handzy, N. Z., Moses, E., Modai, I., and Peled, A. (2007). Transcranial magnetic stimulation at M1 disrupts cognitive networks in schizophrenia. Schizophr. Res. 93, 334-344.

Lewis, M. D., Granic, I., LAmm, C., Zelazo, P. D., Stieben, J., Todd, R. M., Moadab, I., and Pepler, D. (2008). Changes in neural bases of emotion regulation associated 
with clinical improvement in children with behavior problems. Dev. Psychopathol. 20, 913-939.

Liss, M., Mailloux, J., and Erchull, M. J. (2008). The relationships between sensory processing sensitivity, alexithymia, autism, depression and anxiety. Pers. Individ. Dif. $45,255-259$.

Liss, M., Saulnier, C., Fein, D., and Kinsbourne, M. (2006). Sensory and attention abnormalities in autistic spectrum disorders. Autism $10,155-172$.

Liss, M., Timmel, L., Baxley, K., and Killingsworth, P. (2005). Sensory processing sensitivity and its relation to parental bonding, anxiety, and depression. Pers. Individ. Dif. 39, 1429-1439.

Mangeot, S. D., Miller, L. I., Mclntosh, D. N., McGrath-Clarke, J., Simon, J., Hagerman, R. L., and Goldson, E. (2001). Sensory modulation dysfunction in children with attention deficit hyperactivity disorder. Dev. Med. Child Neurol. 43, 399-406.

Manschreck, T. C., Maher, B. A., Waller, N. G., Ames, D., and Latham, C. A. (1985). Deficient motor synchrony in schizophrenic disorder: clinical correlates. Biol. Psychiatry 20, 990-1002.

Masten, A. S. (2001). Ordinary magic: resilience processes in development. Am. Psychol. 56, 227-238.

Masten, A. S. (2006). Developmental psychopathology: pathways to the future. Int. J. Behav. Dev. 30, 47-54.

McFarlane, A. C., Weber, D. L., and Clark, C. R. (1993). Abnormal stimulus processing in posttraumatic stress disorder. Biol. Psychiatry 34, 311-320.

Menon, V. (2011). Large-scale brain networks and psychopathology: a unifying triple network model. Trends Cogn. Sci. 15, 483-506.

Meyer, B., Ajchenbrenner, M., and Bowles, D. P. (2005). Sensory sensitivity, attachment experiences, and rejection responses among adults with borderline and avoidant features. J. Pers. Disord. 19, 641-658.

Meyer, B., and Caver, C. S. (2000). Negative childhood accounts, sensitivity, and pessimism: a study of avoidant personality disorder features in college students. J. Pers. Disord. 14, 233-248.

Mittal, V. A., Tessner, K. D., Trottman, H. D., Esterberg, M., Dhruv, S. H., Simeonova, D. I., McMillan, A. L., Murphy, E., Saczawa, M. E., and Walker, E. F. (2007). Movement abnormalities and the progression of prodromal symptomatology in adolescents at risk for psychotic disorder. J. Abnorm. Psychol. 2, 260-226.

Modell, S., Ising, M., Holsboer, F., and Lauer, C. J. (2005). The Munich vulnerability study on affective disorders: premorbid polysomnographic profile of affected high-risk probands. Biol. Psychiatry 58, 694-699.

Neal, J., Edelmann, R. J., and Glachan, M. (2002). Behavioral inhibition and symptoms of anxiety and depression: is there a specific relationship with social phobia? $\mathrm{Br}$. J. Clin. Psychol. 41, 361-374.

Neelam, K., Garg, D., and Marshall, M. (2011). A systematic review and meta-analysis of neurological soft signs in relatives of people with schizophrenia. BMC Psychiatry 11, 139-146.

Negash, A., Kebede, D., Alem, A., Melaku, Z., Deyessa, N., Shibire, T. Fekadu, A., Fekadu, D., Jacobsson, L., and Kullgren, G. (2004). Neurological soft signs in bipolar I disorder patients. J. Affect. Disord. $80,221-230$.

Neumann, C. S., and Walker, E. F. (2003). Neuromotor functioning in adolescents with schizotypal personality disorder: associations with symptoms and neurocognition. Schizophr. Bull. 29, 285-298.

Ong, S. H., Wickramaratne, P., Tang, M., and Weissman, M. M. (2006). Early childhood sleep and eating problems as predictors of adolescent and adult mood and anxiety disorders. J. Affect. Disord. 96, 1-8.

Ornitz, E. M. (1974). The modulation of sensory input and motor output in autistic children. J. Autism Child. Schizophr. 4, 197-215.

Owens, J. A., Maxim, R., Nobile, C., McGuinn, M., and Msall, M. (2002). Parental and self-report of sleep in children with attentiondeficit/hyperactivity disorder. Arch. Pediatr. Adolesc. Med. 154, 549-555.

Ozonoff, S., Young, G. S., Goldring, S., Greiss-Hess, L., Herrera, A. M. Steele, J., Macari, S., Hepburn, S., and Rogers, S. J. (2008). Gross motor development, movement abnormalities, and early identification of autism. I. Autism Dev. Disord. 38, 644-656.

Parush, S., Sohmer, H., Strinberg, A., and Kaitz, M. (2007) Somatosensory function in boys with ADHD and tactile defensiveness. Physiol. Behav. 90, 553-558.

Piazza, C. C., Fisher, W. F., and Kahng, S. W. (1996). Sleep patterns in children and young adults with mental retardation and severe behavior disorders. Dev. Med. Child Neurol. 38, 335-344.

Piek, J. P., Bradbury, G. S., Elsley, S. C., and Tate, L. (2008). Motor coordination and social-emotional behaviour in preschool aged children. Int. J. Disabil. Dev. Educ. 55, 143-151.

Piek, J. P., Pitcher, T. M., and Hay, D. A. (1999). Motor coordination and kinaesthesis in boys with attention deficit hyperactivity disorder. Dev. Med. Child Neurol. 41, 159-165.

Pievani, M., de Haan, W., Wu, T., Seeley, W. W., and Frisoni, G. B. (2011). Functional network disruption in the degenerative dementias. Lancet Neurol. 10, 829-843.

Pine, D., Shaffer, D., and Schonfeld, I. S. (1993). Persistent emotional disorder in children with neurological soft signs. J. Am. Acad. Child Adolesc. Psychiatry 32, 1229-1236.

Quirós, J. B. (1976). Diagnosis of vestibular disorders in the learning disabled. J. Learn. Disabil. 9, 50-58.

Reynolds, S., and Lane, S. J. (2008). Diagnosis validity of sensory overresponsivity: a review of the literature and case reports. J. Autism Dev. Disord. 38, 516-529.

Richdale, A. L., and Schreck, K. A (2009). Sleep problems in autism spectrum disorders: prevalence, nature and possible biopsychosocial aetiologies. Sleep Med. Rev. 13, 403-411.

Rogers, S. J. (2009). What are infant siblings teaching us about autism in infancy? Autism Res. 2, 125-137.

Sanders, R. E., and Keshavan, M. S. (1998). The neurologic examination in adult psychiatry: From soft signs to hard science. J. Neuropsychiatr. 10, 395-404.

Sakar, S., Katshu, M. Z., Nizamie, S. H., and Praharaj, S. K. (2010). Slow wave sleep deficits as a trait marker in patients with schizophrenia. Schizophr. Res. 124, 127-133.

Sanz-Arigita, E. J., Schoonheim, M. M., Damoiseaux, J. S., Rombouts, S. A. R. B., Maris, E., Barkhof, F, Scheltens, P., and Stam, C. J. (2010). Loss of "small-world" networks in Alzheimer's disease: graph analysis of fMRI resting-state functional connectivity. PLoS One 5, el3788. doi: 10.1371/journal.pone.0013788

Schiffman, J., Sorensen, H., Maeda, J., Mrtensen, E. L., Victoroff, J., Hayashi, K., Michelsen, N. M., Ekstorom, M., and Mednick, S (2009). Childhood motor coordination and adult schizophrenia spectrum disorder. Am. J. Psychiatry 166 1041-1047.

Schreck, K. A., Williams, K., and Smith, A. F. (2004). A comparison of eating behaviors between children with and without autism. J. Autism Dev. Disord. 34, 433-438.

Seidl, U., Thomann, P. A., and Schröder, J. (2009). Neurological soft signs in nursing home residents with Alzheimer's disease. $J$. Alzheimers Dis. 18, 525-532.

Shaffer, D., Schonfeld, I., O'Connor, P. A., Stokman, C., Trautman, P., Shafer, S., and Ng, S. (1985). Neurological soft signs: their relationship to psychiatric disorder and intelligence in childhood and adolescence. Arch. Gen. Psychiatry 42, 342-351.

Shefer, S., Gordon, C., Avraham, K. B., and Mintz, M. (2010). Progressive vestibular mutation lead to elevated anxiety. Brain Res. 1317, 157-164.

Shochat, T., Tzischinsky, O., and EngelYeger, B. (2009). Sensory hypersensitivity as a contributing factor in the relation between sleep and behavioral disorders in normal school children. Behav. Sleep Med. 7, 53-62.

Sporns, O. (2010). Networks of the Brain. Cambridge, MA: MIT Press.

Stam, C. J., de Haan, W., Daffertshofer, A., Jones, B. F., Manshanden, I., van Cappellen van Walsum, A. M., Montez, T., Verbunt, J. P. A., de Munck, J. C., van Dijk, B. W., Berendse, H. W., and Scheltens, P. (2009). Graph theoretical analysis of magnetoencephalographic functional connectivity in Alzheimer's disease. Brain 132, 213-224.

Stam, C. J., Jones, B. F., Nolte, G., Breakspear, M., and Scheltens, P. (2007). Small-world networks and functional connectivity in Alzheimer's disease. Cereb. Cortex 17, 92-99.

Steinberg, M., and Rendle-Short, J. (1977). Vestibular dysfunction in young children with minor neurological impairment. Dev. Med. Child Neurol. 19, 639-651.

Supekar, K., Menon, V., Rubin, D., Musen, M., and Greicius, M. D. (2008). Network analysis of intrinsic functional brain connectivity in Alzheimer's disease. PLoS Comput. Biol. 4, e1000100. doi: 10.1371/journal.pcbi. 1000100

Tani, P., Lindberg, N., appelberg, B., Nieninen-von Wendt, T., vonWendt, L., and Porkka-Hieskanen T. (2006). Clinical neurological abnormalities in young adults with Asperger. Psychiatry Clin. Neurosci. 60, 253-255.

Thomann, P. A., Wüstenberg, T., Santos, V. D., Bachmann, S., Essig, M., and Schröder, J. (2009). Neurological soft signs and brain morphology in 
first-episode schizophrenia. Psychol. Med. 39, 371-379.

Udal, A. H., Malt, U. F., Lövdahl, H., Gjaerum, B., Pripp, A. H., and Groholt, B. (2009). Motor function may differentiate attention deficit hyperactivity disorder from early onset bipolar disorder. Behav. Brain Funct. 5, 47-57.

van den Heuvel, M. P., Mandl, R. C. W., Stam, C. J., Kahn, R. S., and Hulshoff Pol, H. E. (2010). Aberrant frontal and temporal complex network structure in schizophrenia: a graph theoretical analysis. $J$. Neurosci. 30, 15915-15925.

Vialou, V., Robison, A. J., LaPlant, Q. C., Covington, H. E., Dietz, D. M., Ohnishi, Y. N., Mouzon, E., Rush, A. J., Watts, E. L., Wallace, D. L., Iňiguez, S. D., Ohnishi, Y. H., Steiner, M. A., Warren, B. L., Krishnan, V., Bolaňos, C. A., Neve, R. L., Ghoes, S., Berton, O., Tamminga, C. A., and Nestler, E. J. (2010). $\Delta$ FosB in brain reward circuits mediates resilience to stress and antidepressant responses. Nat. Neurosci. 13, 745-752.

Viholainen, H., Ahonen, T., Lyytinen, P., Cantell, M., olvanen, A., and Lyytinen, H. (2006). Early motor development and later language and reading skills in children at risk of familial dyslexia. Dev. Med. Child Neurol. 48, 367-373.

Walker, E. F., Lewis, N., Loewy, R., and Palyo, S. (1999). Motor dysfunction and risk for schizophrenia. Dev. Psychopathol. 11, 509-523.

Wang, G., Grone, B., Colas, D., Appelbaum, L., and Mourrain, P. (2011). Synaptic plasticity in sleep: learning, homeostasis and disease. Trends Neurosci. 34, 452-463.

Wang, L., Zhu, C., He, Y., Zang, Y., Cao, Q., Zhang, H., Zhong, Q., and Wang, Y. (2009). Altered small-world brain functional networks in children with attention deficit/hyperactivity disorder. Hum. Brain Mapp. 30, 638-649.

Wen, W., He, Y., and Sachdev, P. (2011). Structural brain networks and neuropsychiatric disorders. Curr. Opin. Psychiatry 24, 219-225.

Yao, Z., Zhang, Y., Lin, L., Zhou, Y., Xu, C., and Jiang, T. (2010). Abnormal cortical networks in mild cognitive impairment and Alzheimer's disease. PLoS Comput. Biol. 6, e1001006. doi: 10.1371/journal.pcbi.1001006

Yesavage, J. A., Friedman, L., Kraemer, H., Tinklenberg, J. R., Salehi, A., Noda, A., Taylor, J. L., O’Hara, R., and Murphy, G. (2004). Sleep/wake disruption in Alzheimer's disease: APOE status and longitudinal course. J. Geriatr. Psychiatry Neurol. $17,20-24$

Yochman, A., Parush, S., and Ornoy, A. (2004). Responses of preschool children with and without ADHD to sensory events in daily life. Am. J. Occup. Ther. 58, 294-302.
Conflict of Interest Statement: The authors declare that the research was conducted in the absence of any commercial or financial relationships that could be construed as a potential conflict of interest.

Received: 20 November 2011; paper pending published: 25 November 2011; accepted: 21 January 2012; published online: 07 February 2012.

Citation: Levit-Binnun $N$ and Golland $Y$ (2012) Finding behavioral and network indicators of brain vulnerability. Front. Hum. Neurosci. 6:10. doi: 10.3389/fnhum.2012.00010

Copyright (c) 2012 Levit-Binnun and Golland. This is an open-access article distributed under the terms of the Creative Commons Attribution Non Commercial License, which permits non-commercial use, distribution, and reproduction in other forums, provided the original authors and source are credited. 